\title{
Distance-Based Paper Device Combined with Headspace Extraction for Determination of Cyanide
}

\author{
Papichaya Khatha ${ }^{1}$, Thanyarat Phutthaphongloet ${ }^{1}$ (), Phenphitcha Timpa ${ }^{1}$, \\ Benjawan Ninwong ${ }^{1}$, Kamolwich Income ${ }^{1,2}$, Nalin Ratnarathorn ${ }^{1,2}$ and Wijitar Dungchai ${ }^{1,2, *(1)}$ \\ 1 Organic Synthesis, Electrochemistry \& Natural Product Research Unit, Department of Chemistry, \\ Faculty of Science, King Mongkut's University of Technology Thonburi, Prachautid Road, Thungkru, \\ Bangkok 10140, Thailand; papichaya18@gmail.com (P.K.); thanyarat.phut@gmail.com (T.P.); \\ f_phenphitcha@outlook.co.th (P.T.); ben-benone@hotmail.com (B.N.); kamolwich_in@hotmail.com (K.I.); \\ Nalinratnarathorn@gmail.com (N.R.) \\ 2 Applied Science \& Engineering for Social Solution Unit, Faculty of Science, \\ King Mongkut's University of Technology Thonburi, Prachautid Road, Thungkru, Bangkok 10140, Thailand \\ * Correspondence: wijitar.dun@kmutt.ac.th; Tel.: +66-2-470-9553; Fax: +66-2-470-8840
}

Received: 22 April 2019; Accepted: 17 May 2019; Published: 21 May 2019

\begin{abstract}
We report for the first time a distance-based paper device based on gold/silver core shell nanoparticles (Au@Ag NPs) for a simple, inexpensive, instrument-free, and portable determination of cyanide by the naked eye. Au@Ag NPs immobilized on a paper channel were etched by cyanide ions so that a yellow color band length of Au@Ag NPs is proportional to a decrease in the cyanide concentration. Quantification is achieved by measuring color length, thus eliminating the need to differentiate hues and intensities by the user, and the processing data of each imaging device. Moreover, the paper-based headspace extraction was combined with the distance-based paper device to improve the sensitivity. The enrichment factor was found to be 30-fold and the linearity was found in the range $0.05-1 \mathrm{mg} \mathrm{L}^{-1}$. The naked eye detection limit was $10 \mu \mathrm{g} \mathrm{L}^{-1}$ where the World Health Organization (WHO) have regulated the maximum level of cyanide in drinking water as $70 \mu \mathrm{g} \mathrm{L}^{-1}$. Our proposed device also showed no interference from common cations and anions presenting in seawater and waste water including thiocyanate, chloride. Finally, our device has been successfully applied to determine cyanide ions in seawater, drinking water, tap water and wastewater providing satisfactory precision and accuracy.
\end{abstract}

Keywords: distance-based paper device; paper-based headspace extraction; cyanide

\section{Introduction}

Cyanide is a highly poisonous compound commonly used in industries such as gold mining, electroplating, burning of municipal waste and pesticides that can be released in the environment. The most toxic form of cyanide is free cyanide including cyanide ion and hydrogen cyanide (HCN). The cyanide remains in solution as ions at $\mathrm{pH}>11$, while the cyanide will exist as HCN at more acidic than $\mathrm{pH} 5$ [1]. The World Health Organization (WHO) have regulated the maximum level of cyanide in drinking water as $70 \mu \mathrm{g} \mathrm{L}{ }^{-1}$ and the U.S. Environmental Protection Agency (EPA) has established a maximum cyanide contamination level of $200 \mu \mathrm{g} \mathrm{L}^{-1}$ in ambient water [2]. In unpolluted air, the concentration of $\mathrm{HCN}$ is less than 0.2 parts of $\mathrm{HCN}$ per million of air volume [3]. Various methods for the determination of cyanide have been developed such as gas chromatography [4,5], electrochemistry [6,7], chemiluminescence [8], and capillary electrophoresis [9]. Although these methods provide a high sensitivity and selectivity, most of them require instruments or skilled technicians, and are consequently not suitable for field monitoring. 
Recently, nanoparticle-based colorimetric sensors have attracted attention for their simple and high-throughput determination of cyanide $[10,11]$. The bimetallic nanoparticles for a cyanide colorimetric sensor have been also reported to improve visual resolution and provide a low detection limit of cyanide [12,13]. For example, Zeng et al. [12] found the detection limit of cyanide to $10.4 \mu \mathrm{g} \mathrm{L}^{-1}$ by using Au@Ag core shell nanoparticles. Li, et al. [13] reported Ag@Au core shell nanoparticles for the detection of cyanide with limit of detection (LOD) as $4.2 \mu \mathrm{g} \mathrm{L}{ }^{-1}$ and the cyanide level can be semi-quantitatively detected by the naked eye. Unfortunately, these assays are limited by the need of a spectrometer for quantitative analysis as well as the large sample and nanoparticle reagent $(\mathrm{mL})$ consumption. In an effort to conduct a quantitative analysis of cyanide using instrument-free, paper-based analytical devices, a smart phone and scanner assisted detection have the potential to be good alternatives over others due to their ease of use, low cost, less need for reagents and sample consumption, rapid analysis, and portability $[14,15]$. Although smart phones and scanners can distinguish changes in color intensity to quantify cyanide, there are some limitations. Smart phone-based detection needs a black cardboard box to eliminate the lighting effect [15]. Another assay cannot use to detect cyanide directly due to thiocyanate interference [14]. They need to quantify cyanide by using the difference between amount of thiocyanate and cyanide including thiocyanate. Furthermore, the recoveries of cyanide in spiked seawater was lower than $80 \%$ because they lack the interference study of some anions presenting in seawater such as chloride. To overcome their limitations, we developed distance-based paper device for the cyanide quantitative analysis by naked eye. The length of a yellow colored band of Au@Ag core shell nanoparticles from etching reaction increased linearly with cyanide concentration. Many researchers have applied distance-based paper device for the determination of glucose, nickel and glutathione [16], aerosol oxidative activity [17], chloride ion [18], lactoferrin [19], and heavy metals [16,20]. However, they had never been reported for the determination of cyanide. Moreover, paper-based headspace extraction has been developed to enhance the sensitivity and selectivity for sulfite [21], sulfur dioxide [22], volatile organic compounds [23], hydrogen sulfide [24], arsenic [25], and zinc [26] determination. Cyanide will exist as $\mathrm{HCN}$ at more acidic than $\mathrm{pH} 5$ so paper-based headspace extraction can be applied for the highly sensitive and selective determination of cyanide.

In this work, a distance-based paper device coupled with headspace extraction was developed for the naked-eye detection of cyanide by using the etching reaction of Au@Ag core shell nanoparticles. When drop cyanide solution, a yellow color of $\mathrm{Au@Ag} \mathrm{core} \mathrm{shell} \mathrm{nanoparticles} \mathrm{in} \mathrm{a} \mathrm{paper} \mathrm{channel}$ changes to colorless by cyanide etching reaction. Quantitative analysis can be achieved by measuring the length of the colorless band. Our proposed device shows high selectivity, low cost, simplicity, instrument-free and portability for the determination of cyanide by unskilled personnel. Finally, our device has been successfully applied to determine cyanide ions in real water samples providing satisfactory precision and accuracy.

\section{Materials and Methods}

\subsection{Chemicals and Materials}

Chloroauric acid trihydrate $\left(\mathrm{HAuCl}_{4} \cdot 3 \mathrm{H}_{2} \mathrm{O}\right)$, Silver nitrate $\left(\mathrm{AgNO}_{3}\right), \mathrm{L}$-ascorbic acid (AA), Sodium hydroxide $(\mathrm{NaOH})$, anion salts $\left(\mathrm{Na}_{2} \mathrm{SO}_{4}, \mathrm{NaCl}, \mathrm{NaNO}_{3}, \mathrm{Na}_{2} \mathrm{HPO}_{4}, \mathrm{NaHS} \cdot \mathrm{H}_{2} \mathrm{O}, \mathrm{NaF}, \mathrm{NaBr}, \mathrm{NaI}\right.$ and $\mathrm{KSCN})$, cation salts $\left(\mathrm{Al}\left(\mathrm{SO}_{4}\right)_{2} \cdot 18 \mathrm{H}_{2} \mathrm{O}, \mathrm{CuSO}_{4} \cdot 5 \mathrm{H}_{2} \mathrm{O}, \mathrm{ZnSO}_{4} \cdot 7 \mathrm{H}_{2} \mathrm{O}, \mathrm{HgCl}_{2}, \mathrm{~Pb}\left(\mathrm{NO}_{3}\right)_{2}, \mathrm{Fe}\left(\mathrm{NO}_{3}\right)_{3}, \mathrm{FeSO}_{4}\right.$, $\mathrm{CaCO}_{3}, \mathrm{MgSO}_{4} \cdot 7 \mathrm{H}_{2} \mathrm{O}, \mathrm{NiSO}_{4} \cdot 6 \mathrm{H}_{2} \mathrm{O}, \mathrm{CrN}_{3} \mathrm{O}_{9} \cdot 9 \mathrm{H}_{2} \mathrm{O}, \mathrm{CdSO}_{4}, \mathrm{CoSO}_{4} \cdot 7 \mathrm{H}_{2} \mathrm{O}$ ) were obtained from Merck, Germany. All chemicals used in experiment were analytical reagent (AR grade).

\subsection{Instrumentation}

The absorption spectra were measured by UV-Visible spectrometer (Lambda 35, Perkin15 Elmer Instruments, Massachusetts City, MA, USA) at the wavelength 300-800 nm using quartz cuvettes (1.0 cm path length) to characterize gold nanoparticles (AuNPs), silver nanoparticles (AgNPs) and gold@silver core-shell nanoparticles (Au@Ag NPs). TEM images were performed using Transmission Electron Microscope (TEM, JEOL, JEM-2010) to analyze the nanoparticle sizes and shapes. 


\subsection{Synthesis of Gold, Silver and Gold@silver Core-Shell Nanoparticles}

Gold nanoparticles (AuNPs) solution was prepared according to bio-green method and Turkevich method [27]. Briefly, $95 \mathrm{~mL}$ of $5 \mathrm{mM} \mathrm{HAuCl}_{4} \cdot 3 \mathrm{H}_{2} \mathrm{O}$ in $0.01 \%(\mathrm{w} / \mathrm{v})$ soluble commercial starch was freshly prepared and boiled for $30 \mathrm{~min}$ with stirring followed by adding $5 \mathrm{~mL}$ of $0.5 \%(\mathrm{v} / \mathrm{v})$ tri-sodium citrate. Then, the solution was continually boiled for $15 \mathrm{~min}$ and cooled down to room temperature. The color change of AuNPs solution from pink to red wine was observed by naked eye. The shape and particle size distributions of the obtained AuNPs were confirmed with TEM.

Silver nanoparticles (AgNPs) solution was prepared by using silver nitrate $\left(\mathrm{AgNO}_{3}\right)$ in the presence of starch solution as reducing agent. Briefly, the $\mathrm{AgNO}_{3}$ solution was added to starch solution drop by drop during at a flow rate of $2 \mathrm{~mL} \mathrm{~s}^{-1}$. Solution was stirred vigorously during this process at room temperature. For indicating the formation of the small silver nanoparticles, the color change was noticeable from colorless to dark yellow. Then, AgNPs solution was boiled for $2 \mathrm{~h}$ and cooled down to room temperature for $12 \mathrm{~h}$. The shape and particle size distributions of the obtained AgNPs were confirmed with TEM.

For a preparation of Au@Ag NPs, $200 \mu \mathrm{L}$ of $1000 \mathrm{mg} \mathrm{L}^{-1} \mathrm{AgNO}_{3}$ was mixed with $300 \mu \mathrm{L}$ of the prepared AuNPs solution acting as the core. Then, $200 \mu \mathrm{L}$ of $500 \mathrm{mg} \mathrm{L}^{-1}$ ascorbic acid and $300 \mu \mathrm{L}$ of $0.01 \mathrm{M} \mathrm{NaOH}$ were added to the mixture solution. After that, the solution turned into yellow immediately. Finally, the Au@Ag NPs products were characterized using TEM and UV-Visible spectrophotometry.

\subsection{Device Fabrication}

Using CorelDraw to design the pattern of the device in the shape of a thermometer that consisted of a sample zone (diameter $7 \mathrm{~mm}$ ) and a straight channel for detection zone with a width $2 \mathrm{~mm}$ and length of channel $40 \mathrm{~mm}$. The width of the hydrophobic wax was $1 \mathrm{~mm}$. Then, designed was printed onto Whatman No.1 filter paper using a wax printer (Xerox ColorQube 8870, Yokohama, Japan). The device was heated at $150{ }^{\circ} \mathrm{C}$ in an oven for $2 \mathrm{~min}$ and then cooled to room temperature. To prevent solution leakage through the device, tape was sealed with the back side of the device. For analysis, $7 \mu \mathrm{L}$ of $2.19 \times 10^{-11} \mathrm{~mol} \mathrm{~L}^{-1} \mathrm{Au} @ \mathrm{Ag}$ NPs were spotted onto the detection channel and allowed to dry. After that, $50 \mu \mathrm{L}$ of standard or sample solution was added onto the sample zone and flowed through the detection channel by capillary action.

\subsection{Optimization of Detection Conditions on Distance-Based Paper Devices}

The distance-based paper devices (dPADs) were optimized with various parameters. Firstly, $50 \mu \mathrm{L}$ of $10 \mathrm{mg} \mathrm{L}^{-1}$ cyanide ions were used to determine the optimal conditions. The optimum ratios of AuNPs to $\mathrm{AgNO}_{3}$ for being core-shell structure were studied by using ratio of $0.25 \mathrm{mM}$ AuNPs and $1000 \mathrm{mg} \mathrm{L}^{-1} \mathrm{AgNO}_{3}$ at 3:1, 3:2 and 3:3 (v/v). In addition, the concentration of AuNPs $(0.5,0.25$ and $0.125 \mathrm{mM}), \mathrm{AgNO}_{3}\left(500,800,1000,1500\right.$ and $\left.2000 \mathrm{mg} \mathrm{L}^{-1}\right)$, L-ascorbic acid (300, 500, 1000, 1500 and $\left.2000 \mathrm{mg} \mathrm{L}^{-1}\right)$ and $\mathrm{NaOH}(0.0001,0.001,0.01,0.1$ and $1 \mathrm{M})$ were optimized respectively. Then, the effect of reactions times in range $0-45 \mathrm{~min}$ and the $\mathrm{pH}$ of samples in the range of 8-14 were evaluated.

\subsection{Applications for Real Samples}

The proposed method was applied for the determination of cyanide in the extracted mining wastewater sample and seawater. For first part, the sample was analyzed by Ion chromatography (IC). Moreover, the sample was analyzed with our device to compare with IC results. Prior to analysis, samples were prepared by paper-based head-space extraction for all samples (seawater, drinking water, tap water and wastewater) and the distillation for wastewater.

For paper-based headspace extraction, Whatman No.1 filter paper cut to a diameter of $7 \mathrm{~mm}$ was immersed in $1 \mathrm{M} \mathrm{NaOH}$ solution for $30 \mathrm{~min}$. Then, the paper immobilized with $\mathrm{NaOH}$ was hung to the lid of a $25 \mathrm{~mL}$ sample vial. Five $\mathrm{mL}$ of standard cyanide solutions or samples were added to the sample vial. $200 \mu \mathrm{L}$ of concentrated $\mathrm{H}_{2} \mathrm{SO}_{4}$ was injected into the vial and closed with the lid for $30 \mathrm{~min}$. 
Next, the paper was put into sample zone of distance-based paper devices and $50 \mu \mathrm{L}$ of $0.1 \mathrm{M} \mathrm{NaOH}$ was dropped to the sample zone, which carried by capillary action with the flow channel and reacted with Au@Ag NPs through the detection channel as shown in Scheme 1.

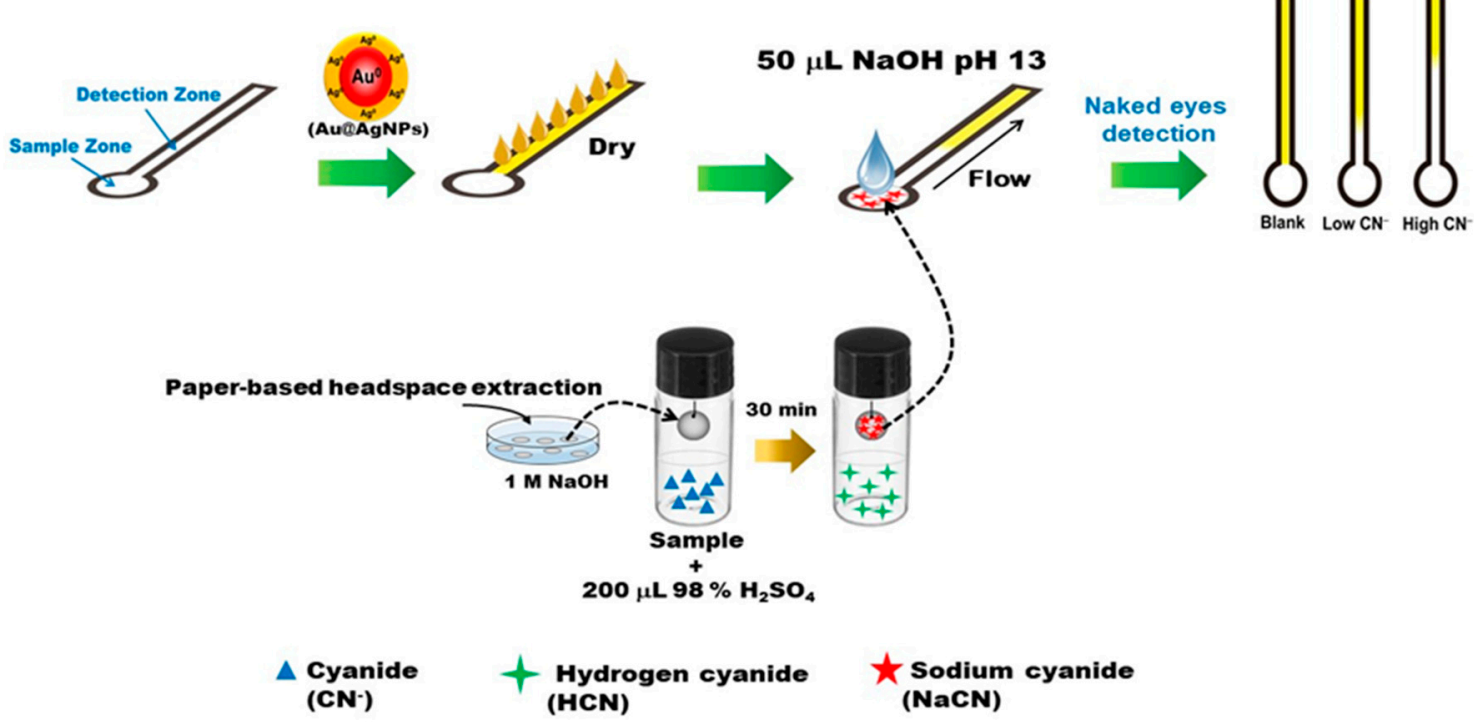

Scheme 1. Schematic design of the distance-based paper sensor designs and general analytical methods.

For wastewater, the total cyanide was distilled using the SimpleDist ${ }^{\mathrm{TM}}$ System [28]. Fifty $\mathrm{mL}$ of sample was added into boiling tube and sealed with the screw cap. It was joined into the collection trap which contained $25 \mathrm{~mL}$ of $0.25 \mathrm{~N} \mathrm{NaOH}$. The vacuum pump was turned on and slowly adjusted valve to provide an air flow bubble rate of 5 bubbles per second for position as viewed in collection trap. Then, $5 \mathrm{~mL}$ of $18 \mathrm{M} \mathrm{H}_{2} \mathrm{SO}_{4}$ was slowly added into the boiling tube though the reagent inlet of screw cap and was put in the heating block at $125^{\circ} \mathrm{C}$ for $30 \mathrm{~min}$ to completely distillation. Finally, the liquid in the collection trap was brought to make the volume up to $50 \mathrm{~mL}$ with DI water. The distilled cyanide from wastewater was analyzed using ion chromatography and the distance-based paper device.

\section{Results and discussion}

\subsection{Characterization of $A u @ A g N P s$}

The Au@Ag NPs were characterized by UV-Visible spectrometer and TEM. The spectra of AuNPs, AgNPs and Au@Ag NPs were shown in Figure 1. AuNPs shows the absorption spectrum at $523 \mathrm{~nm}$ whereas the maximum absorption of Au@Ag NPs was found at $409 \mathrm{~nm}$ as the same wavelength as AgNPs which can identify the Ag nanoshells on Au@Ag NPs. The absorbance of Au@Ag NPs at 409 nm decreased when the increasing of the cyanide concentration in solution. It indicates that Ag nanoshells of Au@Ag NPs were etched by cyanide ions. From TEM images, the particle size of AuNPs, AgNPs, $\mathrm{Au} @ \mathrm{Ag}$ NPs, and Au@Ag NPs with addition of cyanide were 7.31 $\pm 1.55,7.02 \pm 2.44,20.9 \pm 7.11$, and $9.26 \pm 2.77 \mathrm{~nm}$, respectively. The particle size of Au@Ag NPs is larger than AuNPs and TEM image of Au@Ag NPs also exhibited electronic inhomogeneity with a dark core surrounded by a lighter shell (Figure 2c). After adding $50 \mathrm{mg} \mathrm{L}^{-1}$ cyanide, the particle size of Au@Ag NPs decreased from $20.9 \pm 7.11$ to $9.26 \pm 2.77 \mathrm{~nm}$ (Figure 2d). These results confirms that cyanide can etch Ag nanoshells and an Au core sequentially in the presence of oxygen via Equation (1), leading to the change of dimensional particle, which induces visual color changes from yellow to pink and then to colorless in finally.

$$
4 \mathrm{Ag}+8 \mathrm{CN}^{-}+2 \mathrm{H}_{2} \mathrm{O}+\mathrm{O}_{2} \leftrightarrow 4\left[\mathrm{Ag}(\mathrm{CN})_{2}\right]^{-}+4 \mathrm{OH}^{-}
$$

$\mathrm{E}^{0}=0.851 \mathrm{~V}$, Equilibrium constant of this reaction $=9.4 \times 10^{24}$ 


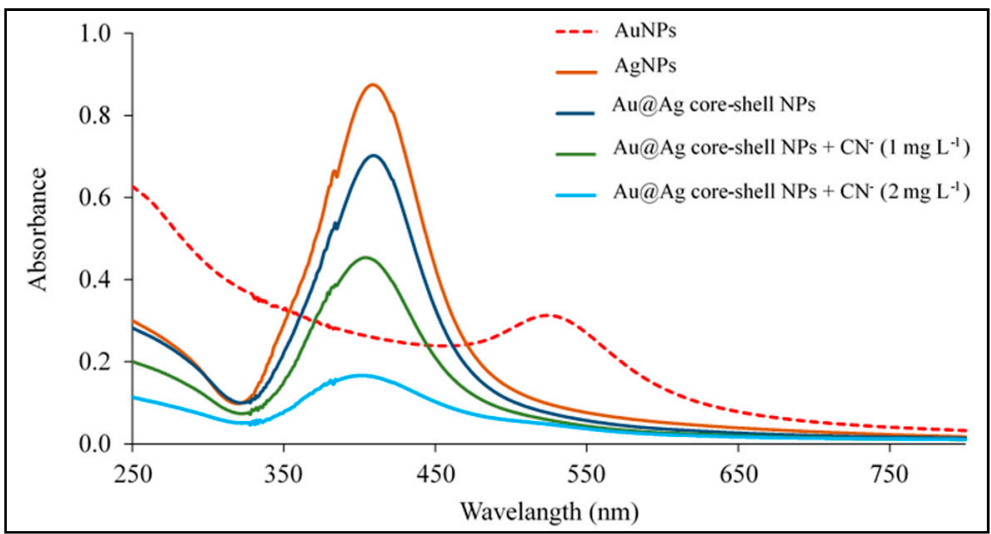

Figure 1. UV-Visible spectra of AuNPs, AgNPs and Au@Ag NPs without and with $\mathrm{CN}^{-}$at 1 and $2 \mathrm{mg} \mathrm{L}^{-1}$.
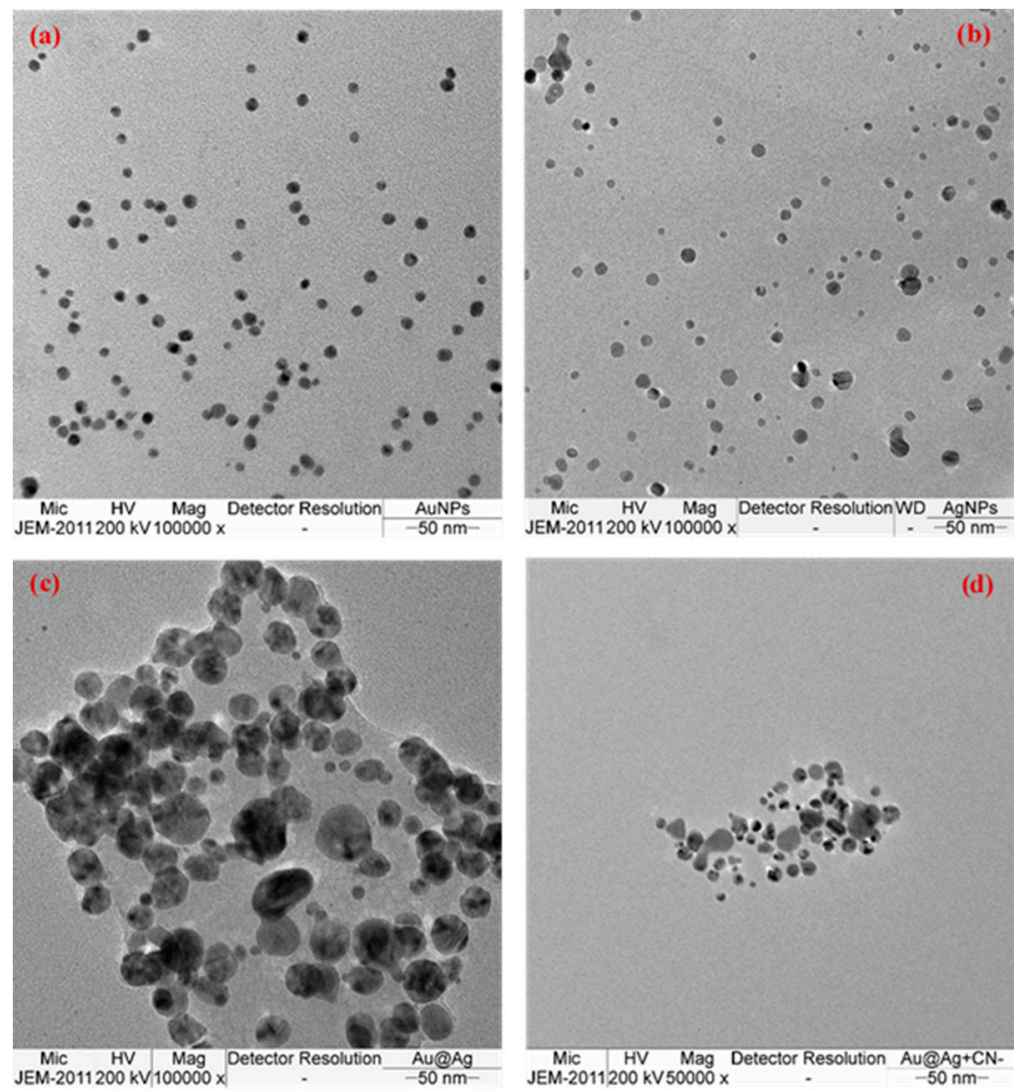

Figure 2. TEM images for (a) AuNPs, (b) AgNPs, (c) Au@Ag NPs and (d) Au@Ag NPs in the presence of $20 \mathrm{mg} \mathrm{L}^{-1} \mathrm{CN}^{-}$.

\subsection{Study of Reagents Influence on the Length of Au@Ag NPs Color Band on dPADs}

The reagent concentration used in the synthesis of bimetallic NPs have a major impact on the shell to core ratio and the thickness of $\mathrm{Ag}$ nanoshells have effect on the sensitivity of cyanide detection. Hence, the AuNPs, $\mathrm{AgNO}_{3}$, ascorbic acid and $\mathrm{NaOH}$ concentration were studied during the preparation of Au@Ag NPs. The concentration of AuNPs was studied at 0.500, 0.250 and $0.125 \mathrm{mM}$. The colorless length of Au@Ag NPs occurring on the white paper channel after the addition of cyanide was no significant difference among three AuNPs concentrations (Figure S1). However, the highest standard deviation (SD) of the colorless band length on dPADs was found at $0.125 \mathrm{mM}$ AuNPs. To obtain high precision and less reagent consumption, the concentration of $0.250 \mathrm{mM}$ was chosen for the synthesis of Au@Ag NPs in the further experimental. Then, the concentration of $\mathrm{AgNO}_{3}$ was investigated in 
the range of 500-2000 $\mathrm{mg} \mathrm{L}^{-1}$. The increase of yellow color intensity was observed when $\mathrm{AgNO}_{3}$ concentration increased. We supported that the thickness of Ag nanoshells expanded at the high $\mathrm{AgNO}_{3}$ concentration. The core/shell NPs with thick silver shells were beneficial for the detection of cyanide on dPADs due to the easy to discriminate the colorless band length by the naked eye, but they suffered from low sensitivity. In contrast, the NPs with thin silver shells were sensitive for the detection of cyanide, but the colorless band length was difficult to resolve by the naked eye (Figure S2). Therefore, the suitable concentration of $\mathrm{AgNO}_{3}$ at $1000 \mathrm{mg} \mathrm{L}^{-1}$ was selected to compromise the sensitivity and the visual discrimination.

Ascorbic acid was used as the reducing agent for the reduction of $\mathrm{Ag}^{+}$to $\mathrm{Ag}^{0}$ during the $\mathrm{Au} @ \mathrm{Ag}$ NPs preparation. The concentration of ascorbic acid was also investigated at 300, 500, 1000, 1500 and $2000 \mathrm{mg} \mathrm{L}^{-1}$. The concentration of $\mathrm{NaOH}$ was investigated in the concentration of $0.0001,0.001$, $0.01,0.1$ and $1 \mathrm{M}$. There was no significant difference of the colorless band length but the best visual resolution between yellow color and colorless band length was found at $500 \mathrm{mg} \mathrm{L}^{-1}$ ascorbic acid and $1 \mathrm{M} \mathrm{NaOH}$ (data not shown). Hence these concentrations were selected as the optimal condition.

\subsection{Optimization of Detection Conditions on dPADs}

The $\mathrm{pH}$ effect of the cyanide solution on the sensitivity was studied in the range of $\mathrm{pH}$ 8-14. The cyanide solution at $\mathrm{pH} 13$ was chosen because the highest colorless band length was found at this condition (Figure 3). The free cyanide consists of $\mathrm{HCN}$ and cyanide ions but $100 \%$ of cyanide ions presents in $\mathrm{pH}>11$. At $\mathrm{pH} 14$, the colorless band distance decreased because the high amount of hydroxide ion can force the backward reaction of equilibrium in Equation (1).

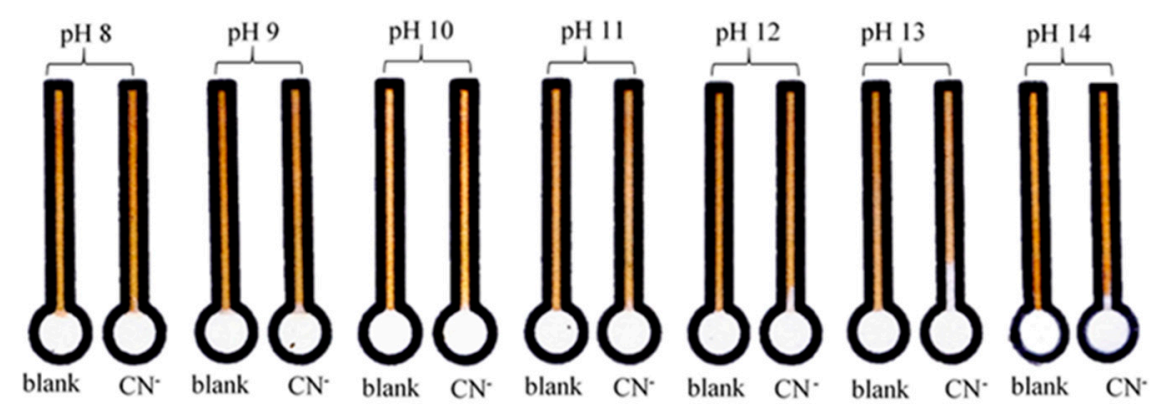

Figure 3. $\mathrm{pH}$ effect in the range of 8-14 with the present of $\mathrm{CN}^{-} 10 \mathrm{mg} \mathrm{L}^{-1}$.

The influence of sample volume was studied in the range of 25-100 $\mu \mathrm{L}$. The sample volume at two times of $50 \mu \mathrm{L}$ gave the highest distance (Figure $4 \mathrm{f})$, but it needs a long analysis time $(90 \mathrm{~min}$.). Although, the sample volume increased, the sensitivity of cyanide detection rose up until $75 \mu \mathrm{L}$ but the analysis time also increased. To obtain the short analysis time, $50 \mu \mathrm{L}$ of sample volume (Figure $4 \mathrm{c}$ ) was chosen as the optimum condition for 40 min analysis time (Figure S3).

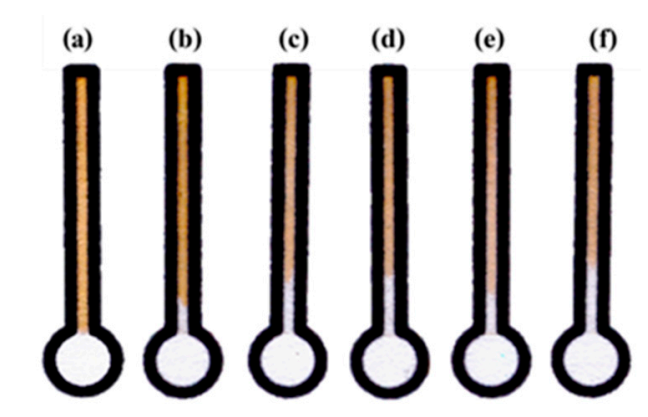

Figure 4. Effect of sample volume at (a) 0 , (b) 25, (c) 50, (d) 75, (e) 100, and (f) $50 \times 2 \mu \mathrm{L}$ contained of $\mathrm{CN}^{-} 10 \mathrm{mg} \mathrm{L}^{-1}$. 
The stability of devices after storing the prepared distance-based paper device was studied for five weeks. The solutions of Au@Ag core-shell NPs were coated on paper devices and allowed dry before storage at $4{ }^{\circ} \mathrm{C}$. The results were measured by the naked eyes, the intensity has no significant difference from freshly prepared paper devices. The distance signal was decreased at $3.3 \%$ after four and five weeks (Figure S4). Thus, this device can be used over than five weeks.

\subsection{Analytical Performance}

The calibration curve for the determination of cyanide was shown in Figure S5. The linear range between the distance signal and the concentration were found to be $1-40 \mathrm{mg} \mathrm{L}^{-1}\left(R^{2}=0.9952\right)$. The limits of detection (LOD) were obtained at the concentrations as low as $1 \mathrm{mg} \mathrm{L}^{-1}$ by naked eyes. The relative standard deviations (\%RSD) of three concentrations which were 5, 20, and $40 \mathrm{mg} \mathrm{L}^{-1}$ and repeated 10 devices in each concentration were $6.68 \%, 7.20 \%$, and $5.38 \%$, respectively. Moreover, the sensitivity was increased by paper-based head-space extraction. The enrichment factor was found to be 30-fold and the calibration was found in the range $0.05-1 \mathrm{mg} \mathrm{L}^{-1}\left(\mathrm{LOD}=10 \mu \mathrm{g} \mathrm{L}^{-1}\right)$ as shown in Figure 5. The linear range is sufficient for monitoring drinking water where the World Health Organization (WHO) have regulated the maximum level of cyanide in drinking water as $70 \mu \mathrm{g} \mathrm{L}^{-1}$ and the U.S. Environmental Protection Agency (EPA) has established a maximum cyanide contamination level of $200 \mu \mathrm{g} \mathrm{L}{ }^{-1}$ in ambient water. Our lowest naked-eye detectable concentration was $10 \mu \mathrm{g} \mathrm{L}^{-1}$. Although our LOD isn't lower than those of paper-based sensing platform $\left(0.7 \mu \mathrm{g} \mathrm{L}^{-1}\right.$ and $0.026 \mathrm{ng}$ $\mathrm{L}^{-1}$ ) [15,16], quantification is achieved by measuring color length. Thus, eliminating the need to differentiate hues and intensities by the user and the processing data of each imaging device.

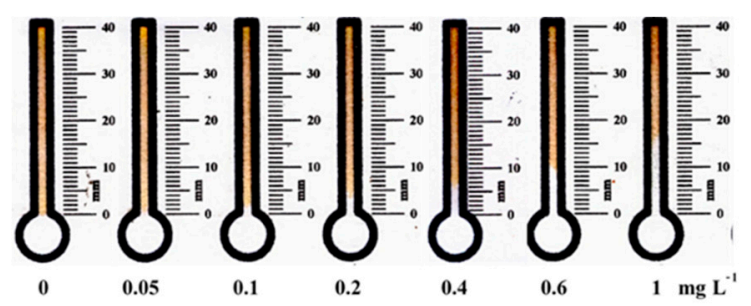

(a)

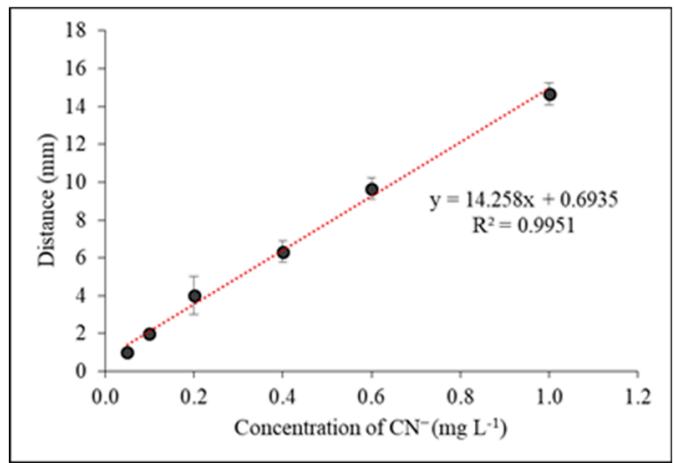

(b)

Figure 5. (a) Result images of $\mathrm{CN}^{-}$determination in the range of $0.05-1 \mathrm{mg} \mathrm{L}^{-1}$ with head-space extraction on APADs and (b) Calibration curve for $\mathrm{CN}^{-}$determination in the range of $0.05-1 \mathrm{mg} \mathrm{L}^{-1}$ with head-space extraction on dPADs.

The selectivity of our proposed device was studied at $10 \mathrm{mg} \mathrm{L}^{-1}$ cyanide, other anions and cations. As a result, shown in Figure 6, the colorless band length did not present with the addition of other ions, except for cyanide ions. Then, the interferences effect for the determination of cyanide were investigated in the ratio of analyte to interference which in 1:1, 1:10 and 1:100 ratios. It was found that over than or approximate to 100 -fold for $\mathrm{SO}_{4}{ }^{2-}, \mathrm{Cl}^{-}, \mathrm{NO}^{3-}, \mathrm{PO}_{4}{ }^{3-}, \mathrm{S}^{2-}, \mathrm{F}^{-}, \mathrm{Br}^{-}, \mathrm{Ca}^{2+}, \mathrm{Cu}^{2+}, \mathrm{Fe}^{2+}$, $\mathrm{Fe}^{3+}, \mathrm{Mg}^{2+}, \mathrm{Pb}^{2+}, \mathrm{Zn}^{2+}, \mathrm{Cd}^{2+}, \mathrm{Co}^{2+}, \mathrm{Cr}^{3+}$ and $\mathrm{Ni}^{2+}$ have no influences on distance signal of $\mathrm{CN}^{-}$. The tolerated ratio of the other interference effected at 100-fold of $\mathrm{I}^{-}, \mathrm{SCN}^{-}$, and $10-$ fold of $\mathrm{Al}^{3+}$ and $\mathrm{Hg}^{2+}$ have an influence on distance signal but it must be emphasized that the $\mathrm{I}^{-}, \mathrm{SCN}^{-}, \mathrm{Al}^{3+}$ and $\mathrm{Hg}^{2+}$ concentration in natural water samples is very low. 


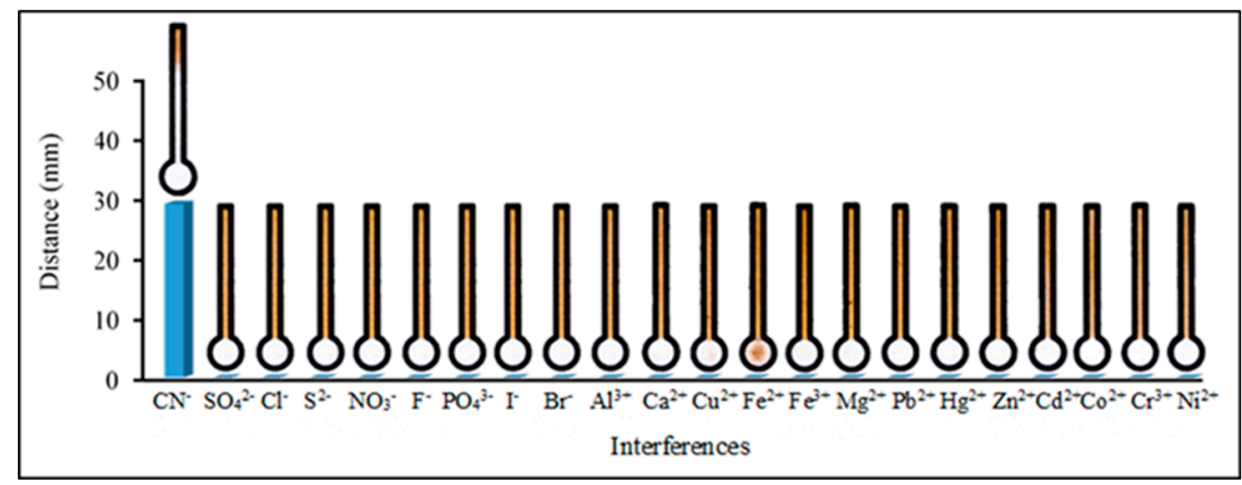

Figure 6. Selectivity of cyanide at $10 \mathrm{mg} \mathrm{L}^{-1} \mathrm{CN}^{-}$, other anions and cations. The bar shows the white distance on paper-based device for anions and cations detection.

\subsection{Applications}

To evaluate the utility of our proposed devices, dPADs were applied to the determination of cyanide in the extracted mining wastewater samples and real water samples. The result of wastewater was shown in Table 1 which was comparison between the developed method and the IC method. No significant difference between two detection methods were found at the $95 \%$ confidence interval by paired $t$-test. The $t_{\text {calculated }}$ ( 0.313 for distillation and 0.273 for headspace extraction) was lower than $\mathrm{t}_{\text {Critical }}$ (4.303). In addition, paper-based head-space extraction coupled on dPADs was successfully applied for the determination of cyanide in seawater, drinking water, and tap water (Table S1). The recovery of two concentrations for spiked level at 70 and $500 \mu \mathrm{g} \mathrm{L}^{-1}$ in seawater, drinking water, and tap water were found in the range of $93 \%-108 \%$. Therefore, our device has been successfully applied to determine cyanide in seawater, drinking water, tap water and waste water providing satisfactory precision $(\%$ RSD $<7.6)$ and accuracy $(93-108 \%)$.

Table 1. Determination of $\mathrm{CN}^{-}$in metallurgical industry wastewater samples.

\begin{tabular}{|c|c|c|}
\hline Samples & $\begin{array}{l}\text { Developed Method }( \pm S D, n=3) \\
\text { Headspace Distillation }\end{array}$ & $\begin{array}{l}\text { IC Method } \\
( \pm S D, n=3)\end{array}$ \\
\hline & $\mathrm{CN}^{-}$found $\left(\mathrm{mg} \mathrm{L}^{-1}\right)$ & $\mathrm{CN}^{-}$found $\left(\mathrm{mg} \mathrm{L}^{-1}\right)$ \\
\hline 1 & $3.96 \pm 0.13 \quad 3.51 \pm 0.17$ & $4.06 \pm 0.08$ \\
\hline 2 & $9.26 \pm 0.14 \quad 8.46 \pm 0.12$ & $8.58 \pm 0.13$ \\
\hline 3 & $9.10 \pm 0.04 \quad 10.58 \pm 0.81$ & $9.43 \pm 0.15$ \\
\hline
\end{tabular}

In summary, the distance-based paper device immobilized by Au@Ag NPs was successfully developed for the low cost, rapid, easy to operate, instrument-free, portable determination of cyanide. This analysis is based on the etching reaction of Au@Ag NPs by cyanide ions. The decrease in a yellow color band length of Au@Ag NPs corresponds to the quantity of cyanide; due to a strong change in the color band, the results can be easily detected by naked eye. Paper-based headspace extraction was also coupled with the distance-based paper device to enhance the sensitivity (30-fold enrichment factor). The limit of detection was obtained at the concentrations as low as $10 \mu \mathrm{g} \mathrm{L}^{-1}$ by naked eyes. Our device could be applied to the low-level detection of cyanide in real samples by unskilled personnel and without interference effects.

Supplementary Materials: The following are available online at http://www.mdpi.com/1424-8220/19/10/2340/s1, Figure S1: The effect of AuNPs for the Au@Ag NPs synthesis with the different concentration of AuNPs at (a) 0.500 , (b) 0.250 and (c) 0.125 with the response signal of $\mathrm{CN}^{-} 10 \mathrm{mg} \mathrm{L}^{-1}$. Figure S2: The effect of $\mathrm{AgNO}_{3}$ for the $\mathrm{Au} @ \mathrm{Ag}$ NPs synthesis with the different concentration of $\mathrm{AgNO}_{3}$ at (a) 500, (b) 800, (c) 1,000, (d) 1,500 and (e) $2,000 \mathrm{mg} \mathrm{L}^{-1}$ on the distance-based paper device with the response signal of $\mathrm{CN}^{-} 10 \mathrm{mg} \mathrm{L}^{-1}$. Figure S3: Detection time for $\mathrm{CN}^{-}$on distance-based device in the range of 0-50 min with $10 \mathrm{mg} \mathrm{L}^{-1} \mathrm{of} \mathrm{CN}^{-}$. Figure S4: Lifetime of $\mathrm{CN}^{-}$on distance-based device. Figure S5: Calibration curve for $\mathrm{CN}^{-}$determination in the range of $1-40 \mathrm{mg} \mathrm{L}^{-1}$. Table S1: Determination of $\mathrm{CN}^{-}$in water samples 
Author Contributions: P.K. performed the dPADs experiment. T.P., P.T., B.N. performed the paper-based headspace extraction. K.I. and N.R. performed the distillation of wastewater. W.D. conducted the research, analysis of data, wrote and revised the manuscript. All authors discussed the results and commented on the manuscript.

Funding: This research received no external funding.

Acknowledgments: W.D. gratefully acknowledges the financial support from Thailand Research Fund. P.K. thanks to the Capacity Building Program for New Research 2019 from National Research Council of Thailand (NRCT) for research funding and Science Faculty, King Mongkut's University of Technology Thonburi.

Conflicts of Interest: The authors declare no conflict of interest.

\section{References}

1. Code, International Cyanide Management. Cyanide Chemistry. Available online: https://www.cyanidecode. org/cyanide-facts/cyanide-chemistry (accessed on 18 February 2019).

2. (EPA), United States Environmental Protection Agency. Ambient Water Quality Criteria for Cyanide; EPA: Washington, DC, USA, 1984.

3. Taylor, J. Toxicological Profile for Cyanide: Agency for Toxic Substances and Disease Registry; ATSDR: Atlanta, GA, USA, 2010.

4. Guojie, L.; Liu, J.; Hara, K.; Wang, Y.; Yu, Y.; Gao, L.; Li, L. Rapid Determination of Cyanide in Human Plasma and Urine by Gas Chromatography-Mass Spectrometry with Two-Step Derivatization. J. Chromatogr. B 2009, 877, 3054-3058.

5. Desharnais, B.; Huppé, G.; Lamarche, M.; Mireault, P.; Skinner, C.D. Cyanide Quantification in Post-Mortem Biological Matrices by Headspace GC-MS. Forensic Sci. Int. 2012, 222, 346-351. [CrossRef]

6. Blaedal, W.J.; Easty, D.B.; Anderson, L.; Farrell, T.R. Potentiometric Determination of Cyanide with an Ion Selective Electrode. Application to Cyanogenic Glycosides in Sudan Grasses. Anal. Chem. 1971, 43, 890-894. [CrossRef]

7. Lindsay, A.E.; O'Hare, D. The Development of an Electrochemical Sensor for the Determination of Cyanide in Physiological Solutions. Anal. Chim. Acta 2006, 558, 158-163. [CrossRef]

8. Lv, J.; Zhang, Z.; Li, J.; Luo, L. A Micro-Chemiluminescence Determination of Cyanide in Whole Blood. Forensic Sci. Int. 2005, 148, 15-19. [CrossRef] [PubMed]

9. Zhang, Q.; Maddukuri, N.; Gong, M. A Direct and Rapid Method to Determine Cyanide in Urine by Capillary Electrophoresis. J. Chromatogr. A 2015, 1414, 158-162. [CrossRef] [PubMed]

10. Hajizadeh, S.; Farhadi, K.; Forough, M.; Sabzi, R.E. Silver Nanoparticles as a Cyanide Colorimetric Sensor in Aqueous Media. Anal. Methods 2011, 3, 2599-2603. [CrossRef]

11. Cheng, C.; Chen, H.Y.; Wu, C.S.; Meena, J.S.; Simon, T.; Ko, F.H. A Highly Sensitive and Selective Cyanide Detection Using a Gold Nanoparticle-Based Dual Fluorescence-Colorimetric Sensor with a Wide Concentration Range. Sens. Actuators B Chem. 2016, 227, 283-290. [CrossRef]

12. Zeng, J.B.; Cao, Y.Y.; Chen, J.J.; Wang, X.D.; Yu, J.F.; Yu, B.B.; Yan, Z.F.; Chen, X. Au@Ag Core/Shell Nanoparticles as Colorimetric Probes for Cyanide Sensing. Nanoscale 2017, 6, 9939-9943. [CrossRef]

13. Li, Y.; Wang, Q.; Zhou, X.; Wen, C.Y.; Yu, J.; Han, X.; Li, X.; Yan, Z.F.; Zeng, J. A Convenient Colorimetric Method for Sensitive and Specific Detection of Cyanide Using Ag@Au Core-Shell Nanoparticles. Sens. Actuators B Chem. 2016, 228, 366-372. [CrossRef]

14. Saraji, M.; Bagheri, N. Paper-Based Headspace Extraction Combined with Digital Image Analysis for Trace Determination of Cyanide in Water Samples. Sens. Actuators B Chem. 2018, 270, 28-34. [CrossRef]

15. İncel, A.; Akın, O.; Çağır, A.; Yıldız, Ü.H.; Demir, M.M. Smart Phone Assisted Detection and Quantification of Cyanide in Drinking Water by Paper Based Sensing Platform. Sens. Actuators B Chem. 2017, 252, 886-893. [CrossRef]

16. Cate, D.M.; Noblitt, S.D.; Volckens, J.; Henry, C.S. Multiplexed Paper Analytical Device for Quantification of Metals Using Distance-Based Detection. Lab Chip 2015, 15, 2808-2818. [CrossRef]

17. Dungchai, W.; Sameenoi, Y.; Chailapakul, O.; Volckens, J.; Henry, C.S. Determination of Aerosol Oxidative Activity Using Silver Nanoparticle Aggregation on Paper-Based Analytical Devices. Analyst 2013, 138, 6766-6773. [CrossRef] 
18. Phoonsawat, K.; Ratnarathorn, N.; Henry, C.S.; Dungchai, W. A Distance-Based Paper Sensor for the Determination of Chloride Ions Using Silver Nanoparticles. Analyst 2018, 143, 3867-3873. [CrossRef]

19. Yamada, K.; Henares, T.G.; Suzuki, K.; Citterio, D. Distance-Based Tear Lactoferrin Assay on Microfluidic Paper Device Using Interfacial Interactions on Surface-Modified Cellulose. ACS Appl. Mater. Interfaces 2015, 7, 24864-24875. [CrossRef]

20. Pratiwi, R.; Nguyen, M.P.; Ibrahim, S.; Yoshioka, N.; Henry, C.S.; Tjahjono, D.H. A Selective Distance-Based Paper Analytical Device for Copper (II) Determination Using a Porphyrin Derivative. Talanta 2017, 174, 493-499. [CrossRef]

21. Shahvar, A.; Saraji, M.; Gordan, H.; Shamsaei, D. Combination of Paper-based thin film microextraction with smartphone-based sensing for sulfite assay in food samples. Talanta 2019, 197, 578-583. [CrossRef]

22. Li, D.; Duan, H.; Ma, Y.; Deng, W. Headspace-sampling paper-based analytical device for colorimetric/surfaceenhanced raman scattering dual sensing of sulfur dioxide in wine. Anal. Chem. 2018, 90, 5719-5727. [CrossRef]

23. Lim, S.H.; Martino, R.; Anikst, V.; Xu, Z.; Mix, S.; Benjamin, R.; Schub, H.; Eiden, M.; Rhodes, P.A.; Banaei, N. Rapid diagnosis of tuberculosis from analysis of urine volatile organic compounds. ACS Sens. 2016, 1, 852-856. [CrossRef]

24. Tang, S.; Qi, T.; Xia, D.; Xu, M.; Xu, M.; Zhu, A.; Shen, W.; Lee, H.K. Smartphone nano-colorimetric determination of hydrogen sulfide in bio samples after silver-sold core-shell nanoprism-based headspace single-drop microextraction. Anal. Chem. 2019, 91, 5888-5895. [CrossRef] [PubMed]

25. Pena-Pereira, F.; Villar-Blanco, L.; Lavilla, I.; Bendicho, C. Test for arsenic speciation in waters based on a paper-based analytical device with scanometric detection. Anal. Chim. Acta 2018, 1011, 1-10. [CrossRef]

26. Huang, K.; Dai, R.; Deng, W.; Guo, S.; Deng, H.; Wei, Y.; Zhou, F.; Long, Y.; Li, J.; Yuan, X.; et al. Gold nanoclusters immobilized paper for visual detection of zinc in whole blood and cells by coupling hydride generation with headspace solid phase extraction. Sens. Actuators B Chem. 2018, 255, 1631-1639. [CrossRef]

27. Turkevich, J.; Stevenson, P.L.; Hillier, J. A study of the nucleation and growth process in the synthesis of colloidal gold. Discuss. Faraday Soc. 1951, 11, 55-75. [CrossRef]

28. Express, Environmental. Simpledist ${ }^{T M}$ System Operating E Instruction Manual; Environmental Express: Charleston, SC, USA, 2015. 